\title{
Modelling and validation of Lactobacillus plantarum fermentations in cereal- based media with different sugar concentrations and buffering capacities
}

\author{
Dimitris Charalampopoulos ${ }^{1}$, José Antonio Vázquez ${ }^{2,3}$ and Severino S. Pandiella ${ }^{3 *}$
}

1 Department of Food Biosciences, The University of Reading

PO Box 226, Reading RG6 6AP, UK

2 Grupo de Reciclado y Valorización de Materiales Residuales Instituto de Investigacións Mariñas (CSIC)

r/ Eduardo Cabello, 6. Vigo-36208. Galicia - Spain

3 Chemical Engineering and Analytical Science The University of Manchester PO Box 88, Sackville Street, Manchester, M60 1QD, UK.

* Corresponding author: Dr Severino S Pandiella, Fax +44(0)161 306 4399, Email: s.pandiella@manchester.ac.uk 


\begin{abstract}
An unstructured mathematical model is proposed to describe the fermentation kinetics of growth, lactic acid production, $\mathrm{pH}$ and sugar consumption by Lactobacillus plantarum as a function of the buffering capacity and initial glucose concentration of the culture media. Initially the experimental data of $L$. plantarum fermentations in synthetic media with different buffering capacity and glucose were fitted to a set of primary models. Later the parameters obtained from these models were used to establish mathematical relationships with the independent variables tested. The models were validated with 6 fermentations of L. plantarum in different cereal-based media. In most cases the propose models adequately describe the biochemical changes taking place during fermentation. These proposed equations and studied effects are promising approach for the optimization and formulation of cereal-based functional foods.
\end{abstract}

Keywords Lactobacillus plantarum; probiotic; mathematical models; cereal-based media; buffering capacity; sugar concentration. 


\section{Introduction}

The mathematical models that are used to simulate a bioprocess can generally be classified as unstructured or structured. In unstructured models the biomass is considered as one entity described only by its concentration. These models do not take into account any changes that could take place in the inner cells. In structured models the biomass is defined and includes intracellular components, such as the RNA content, enzymes, reactants and products [1]. Although the structured models provide a better understanding of the modelled system, unstructured models are mainly used to describe bacterial kinetics in complex natural substrates. This is mainly due to the complexity of the substrates and to the difficulties in obtaining large sets of experimental data for the intracellular components [2].

In food microbiology, mathematical modelling has been mainly applied to predict growth or inactivation of spoilage of bacteria and foodborne pathogens [3-6]. A number of models have been used to describe the sigmoidal curves of bacterial growth, such as the model of Gompertz [7], Richards [8], Stannard et al. [9], Schnute [10], the logistic model and others. These equations can fit cell growth over time and take into account growth inhibition in the stationary phase of growth.

In the last ten years, there has been an increasing interest in modelling the kinetics of beneficial microorganisms in food systems. For lactic acid bacteria (LAB) the models used to describe cell growth are the unstructured and structured equations mentioned earlier. Growth or non-growth related models are also applied to describe the changes of other biochemical compounds and physical properties in these food systems. These changes include primary or secondary 
metabolites concentrations, volatile production as well as rheological and textural properties [1114]. The aim of these models is to mathematically relate the biochemical properties (response variables) to environmental factors (controlling factors), such as temperature, $p H$, water activity and substrate composition. This contributes to a better understanding and control of the fermentation process and helps to clarify how and to what extent the environment will interfere with the behaviour of the strains [11].

In general modelling is performed in two stages. In the first stage the primary models are applied to the experimental data describing the change of a response variable over time. In the second stage secondary models are developed expressing the bio-kinetic parameters derived from the primary models as a function of a single environmental factor. It must be noted that both primary and secondary models are built using data from experiments in synthetic media under carefully controlled conditions. The predictability of the models is then assessed in the complex food systems. LAB research has focused so far in modelling the dependence of the growth rate on temperature and $p H$ at $p H$-controlled conditions [15-17]. Very little research has been done in the secondary modelling of growth when $\mathrm{pH}$ is not controlled, or taking into account other biokinetic parameters, such lactic acid and bacteriocins production [18-22].

On the other hand, cereals are one of the most suitable components for the production of foods contains a probiotic microorganism (in most cases lactic acid bacteria or bifidobacteria) and a prebiotic substrate. Traditionally, probiotic microorganisms have been included in dairy products, meat and fruit juices. The definition and development of new functional foods cereal-based combine the beneficial effects of cereals and health promoting bacteria is a challenging issue $[23,24]$. In this sense, the major biochemical properties affecting the functionality and quality of a 
probiotic-containing food product are the cell population, lactic acid concentration and $p H$. The cell concentration in the end product is an indicator of probiotic functionality, the lactic acid influences the organoleptic properties and also acts as a preservative agent, while the $p H$ is the main factor determining the stability and safety of the product during storage $[25,26]$. Since sugar is the main carbon source used by the cells, knowledge of the sugar kinetics contributes to a better understanding of cell growth and product formation. Moreover, the amount of sugar present in the carrier medium influences the survival of L. plantarum in acidified model solutions imitating stomach conditions.

The aim of this study was to develop a model that would be able to simulate the kinetics of cell growth, lactic acid production, $p H$ drop and sugar consumption in cereal-based fermentations

with L. plantarum. The kinetic parameters of the primary models for these dependent variables were expressed as a function of the initial sugar concentration of the media and their buffering capacity. The models were built using data from fermentations in synthetic media with various levels of glucose and different buffering abilities. Finally, the predictability of the models was evaluated using a variety of cereal-based fermentations of different concentrations. Thus, the numerical parameters obtained allowed the characterisation of these cultures and could be a preliminary step in the formulation of novel potentially probiotic foods.

\section{Materials and methods}

\section{Microorganism and inoculum}

The strain L. plantarum NCIMB 8826 isolated from human saliva was used. It was maintained at $4^{\circ} \mathrm{C}$ and sub-cultured monthly on MRS agar slopes (Oxoid). Isolated colonies from MRS agar 
plates were pre-cultured twice in MRS broth (Oxoid) for approximately $24 \mathrm{~h}$ at $37^{\circ} \mathrm{C}$. The cells were collected by centrifugation (5000 g, $10 \mathrm{~min}, 4^{\circ} \mathrm{C}$ ), washed twice with sterile quarter-strength Ringer's solution and re-suspended in the same solution. The bacterial suspensions used as inocula for the fermentation studies $(1 \% \mathrm{v} / \mathrm{v})$ were obtained from $12 \mathrm{~h}$ pre-cultured cells.

\section{Culture media and microbiological methods}

The synthetic media used for the studies of the buffering capacity and the effect of sugars on $L$. plantarum growth are summarized in Table 1 . The $\mathrm{pH}$ of all media was adjusted to about 5.8 with $1 \mathrm{~N} \mathrm{HCI}$ or $1 \mathrm{~N} \mathrm{NaOH}$ and the media sterilised for $10 \mathrm{~min}$ at $121^{\circ} \mathrm{C}$. Six cereal media were used for model validation: $20 \%$ wheat extract, $30 \%$ barley extract, $40 \%$ barley extract, 30\% barley extract supplemented with $2.2 \mathrm{~g} \mathrm{l}^{-1}$ citric acid, and 5\% and 20\% malt extract. All cereal-based media were prepared as described in Charalampopoulos et al. [27]. In all cases the $p H$ was initially adjusted to about 6.0 with $1 \mathrm{~N} \mathrm{HCI}$ or $1 \mathrm{~N} \mathrm{NaOH}$ and the media sterilised for 30 min at $121^{\circ} \mathrm{C}$.

Shake-flask fermentations were performed in triplicate using $500 \mathrm{~mL}$ screw-capped glass bottles without oxygen control. Bottles were inoculated with a $1 \% \mathrm{v} / \mathrm{v}$ of lactic acid bacteria and incubated at $150 \mathrm{rpm}$ and $37^{\circ} \mathrm{C}$ for 30 or $42 \mathrm{~h}$. The viable cell counting method was used for cell enumeration [28]. Cell growth was monitored by measuring the optical density of the media at $600 \mathrm{~nm}$. The optical density values were transformed to cell counts $\left(\log _{10} \mathrm{cfu} \mathrm{ml} \mathrm{m}^{-1}\right)$ using a preestablished calibration curve. In the fermentation samples $p H$, reducing sugar (as glucose) and lactic acid content were analysed.

\section{Buffering capacity}


The buffering agent used was a $0.2 \mathrm{M}$ acetate buffer stock solution, from which 8 media of different buffering capacity were prepared by dilution (from $1 / 1$ to $1 / 15$ ). The buffering capacity of the media was measured after addition of the nutrient substrate using the method of Pai et al. [29]. $100 \mathrm{ml}$ of each medium were titrated with $1 \mathrm{~N} \mathrm{HCl}$. The values were expressed as the amount of $\mathrm{HCl}$ (mmoles) required to drop one $\mathrm{pH}$ unit per unit volume (1 litre).

\section{Analytical methods}

The dinitrosalicylic acid (DNS) assay was used to measure the reducing sugar concentration in the supernatants of the fermented cereal extracts according to Miller [30]. A standard curve was made using glucose at various concentrations. Lactic acid was measured using an enzymatic kit for D- and L- lactic acid (Boehringer Mannheim).

\section{Numerical and statistical methods}

Fitting procedures and parametric estimations calculated from the results were carried out by minimisation of the sum of quadratic differences between observed and model-predicted values, using the non linear least-squares (quasi-Newton) method provided by the macro 'Solver' of the Microsoft Excel XP spreadsheet. Statistica 6.0 (StatSoft, Inc. 2001) and Mathematica 6 (Wolfram Research, Inc.) programs were used to evaluate the significance of the parameters estimated by fitting of the experimental values to the proposed mathematical models, and the consistency of these equations.

\section{Results and Discussion}

A set of four non-linear algebraic equations comprising the primary models was used to describe 
cell growth $(N)$, lactic acid production $(P), p H$ and sugar concentration $(S)$ with time. The model parameters were estimated from the 17 batch data of $N, P, p H$ and $S$ vs. time. The parameters of the primary models were then fitted to the controlling factors (secondary models) by using linear or non-linear regression analysis. The definition and units of the model parameters and variables are shown in Table 2.

\section{Growth models}

A common model to describe cell population growth is the differential equation proposed by Velhurst in 1844, which includes an inhibition factor of growth. By assuming that inhibition of a population $N$ is proportional to $N^{2}$, the growth rate is given by the following equation

$$
\frac{d N}{d t}=\mu_{m} N\left(\frac{K-N}{K}\right)
$$

Integrating between $N_{0} \rightarrow N$ and $0 \rightarrow t$ gives the biomass concentration as a function of time $[31,32]$

$$
N=\frac{K}{1+\exp \left(c-\mu_{m} t\right)} \text {, with } c=\ln \left(\frac{K}{X_{0}}-1\right)
$$

In order to give biological meaning to the parameters when $\log _{10} N$ are used, equation 2 was reparameterised according to Zwietering et al. [33] 


$$
X=\log \left(\frac{N}{N_{0}}\right)=\frac{A}{1+\exp \left[2+\frac{4 \mu_{m}}{A}(\lambda-t)\right]}
$$

The data of the 17 batch cultures were fitted using equation 3. The optimum parameters with the 95\% confidence intervals and consistence of the equation (Fisher's $F$ test, $\alpha=0.05$ ) are presented in Table 3. In all cases, the fit of results was statistically satisfactory. The mathematical equations were consistent (Fisher's $F$ test) and the parametric estimations were significant (Student's t test). The values predicted by equation 3 are highly correlated with the experimental data with a regression coefficient $r>0.97$.

These results indicate that the logistic model could be used to describe L. plantarum growth in various environmental conditions. This means that the inhibitory effect of the accumulated cell concentration on $\mu_{m}$ (as assumed by equation 1) can explain various types of growth limitations such as low sugar availability. It could also explain the inhibitory effect of $p H$, which illustrated by the fact that $\mu_{m}$ decreases with buffering capacity. Lejeune et al. [34] justify this by pointing out that the cell concentration depends on the amount of nutrients consumed and the lactic acid produced (and consequently the $p H$ ). For these reasons the logistic model, or similar forms of it, have been widely used to model the growth of LAB [35-36].

Since the aim of this study was to create a link between cell growth and the properties of the starting media, the bio-kinetic parameters $\mu_{m}, A$ and $\lambda$ were expressed as a function of buffering capacity and glucose. All the functions were of the form $p(f)=p_{\text {opt }} \times \gamma(f)$, which indicates that an optimum value of the parameter $\left(p_{\text {opt }}\right)$ is obtained when the controlling factor $(f)$ is also optimum. 
The function $\gamma(f)$ describes the response of the growth to changes in the factor $f$, with values of $f$ between 0 (no response) and 1 (optimum response). By assuming that the influence of a factor is independent of other factors, the model describing the combined effects of the factors $f_{1}, f_{2}$, $f_{3}, \ldots, f_{n}$ would then be $p\left(f_{1}, f_{2}, f_{3}, \ldots, f_{n}\right)=p_{\text {opt }} \times \gamma\left(f_{1}, f_{2}, f_{3}, \ldots, f_{n}\right)$. This concept is generally called the $\gamma$-concept and has been extensively used to relate the bio-kinetic parameters describing cell growth (and in fewer cases primary or secondary metabolic activities) to the environmental conditions (usually $\mathrm{pH}$ or temperature) [11,16,37-40].

\section{Secondary modelling of $\mu_{m}$}

Figure 1 (up) shows the effect of glucose (S) on $\mu_{m}$. The data show that $\mu_{m}$ increases with the glucose concentration from 0 to $6 \mathrm{~g} \mathrm{l}^{-1}$, while between 6 and $20 \mathrm{~g} \mathrm{l}^{-1} \mu_{m}$ remains approximately constant. The hyperbolic shape of the trend was described using the Monod model [41]:

$$
\mu_{m}=\mu_{o p t s} \frac{S}{K_{s}+S}
$$

The fit of equation 4 to the $\mu_{m}$ values (obtained from Table 3) was performed by the non-linear least squares method. The fit was satisfactory and the derived parameters were $0.70 \mathrm{~h}^{-1}$ for $\mu_{\text {opts }}$ and $1.5 \mathrm{~g} \mathrm{l}^{-1}$ for $K_{s}$ (see Table 4 for statistical validation)

The small $K_{s}$ value suggests that the sugar requirement of this strain is relatively low, and the strain could be used to ferment media of low sugar content. Venkatesh et al. [42] in $p H$ controlled media monitored growth of $L$. bulgaricus and showed that $K_{s}$ is $p H$ dependent. In the 
present study the buffering capacities of the 8 batches were the same (1.09 mmoles HCI $p H^{-1} \mathrm{l}^{-1}$ ). The $p H$ effect on $K_{s}$ was probably not significant. Burgos-Rubio et al. [43] reported a $K_{s}$ value of $3.36 \mathrm{~g} \mathrm{l}^{-1}$ for $L$. bulgaricus, while Martens et al. [38] did not observe any dependence of $L$. plantarum $\mu_{\text {opts }}$ on the initial sugar concentration of the medium. For this reason they considered a $K_{s}$ value of $0.072 \mathrm{~g} \mathrm{l}^{-1}$, which is the general value for $E$. coli on glucose [44]. It must be pointed out that little information is available in the literature regarding the kinetics of LAB growth in a fermented food product. Most published works study the kinetics of the fermentation process for the optimization of the production of lactic acid in industrial applications. In these cases fermentations are carried out under $p H$-control using media with very high sugar concentrations (60 to $300 \mathrm{~g} \mathrm{l}^{-1}$ ). This is the reason why $K_{s}$ is considered to be very small and usually is neglected.

It can be also observed from the data presented in Table 3 that $\mu_{m}$ increases with the buffering capacity of the medium. This can be attributed to the fact that in media with low buffering capacity the $p H$ drop was greater. The inhibitory effect of $p H$ takes place earlier in the fermentation process, resulting in lower $\mu_{m}$ values. A linear relationship was observed between $\mu_{m}$ and the buffering capacity, and the $\mu_{m}$ value corresponding to the higher buffering capacity (1.09 mmoles $\left.\mathrm{HCl} p H^{-1} \mathrm{l}^{-1}\right)$ was considered to be the optimum value $\left(\mu_{\text {optB }}=0.61 \mathrm{~h}^{-1}\right.$ ) for these working conditions. The relative $\mu_{m}$ values $\left(\mu_{m} / \mu_{\text {optB }}\right)$ were then plotted against the buffering capacity $(B)$ in order to obtain an equation of the form $\mu_{m}=\mu_{o p t B} \times \gamma$ (Figure 1 , down). As $B$ can not be zero the data were centered on the mean values of $B\left(B_{\text {cent }}=B-B_{\text {average }} ; B_{\text {average }}=0.57\right.$ mmoles $p H^{-1} \mathrm{l}^{-1}$ ) [31]. The following linear equation was then used to fit the data 


$$
\frac{\mu_{m}}{\mu_{o p t B}}=\alpha_{1}+\beta_{1}(B-0.57)
$$

The fit was satisfactory $(r=0.98, F$-value $=623.04$, Table 4$)$, which suggests that equation 5 can appropriately describe the dependency of $\mu_{m}$ with the buffering capacity.

By assuming that the influences of sugar and buffering capacity on $\mu_{m}$ are independent, equations 4 and 5 could be combined

$$
\mu_{m}=\mu_{o p t}\left(\frac{S}{K_{s}+S}\right)\left[\alpha_{1}+\beta_{1}(B-0.57)\right]
$$

where $\mu_{\text {opt }}\left(\mathrm{h}^{-1}\right)$ is the $\mu_{m}$ value at the conditions where both controlling factors are at their optimum, which occurs when $B$ is 1.09 mmoles $\mathrm{HCl} \mathrm{pH}^{-1} \mathrm{l}^{-1}$ and $S$ is much greater than $K_{s}$. It must be noted that according to equation 6 , when $S=20 \mathrm{~g} \mathrm{l}^{-1}$ and $B=1.09$ mmoles $\mathrm{HCl} p H^{-1} \mathrm{l}^{-1}$ the value of $\mu_{\text {opt }}$ would be $0.64 \mathrm{~h}^{-1}$, which is slightly higher than the $\mu_{\text {optB }}$ value of $0.61 \mathrm{~h}^{-1}$ calculated experimentally. Of the three possible $\mu_{\text {opt }}$ values $\left(\mu_{\text {opt }}\right.$ obtained from equation $6, \mu_{\text {opts }}$ and $\left.\mu_{o p t B}\right)$, the one with the smaller coefficient of variation is $\mu_{o p t s}$, and this value was the one considered in the equation describing the joint effect (equation 6)

$$
\mu_{m}=0.70\left(\frac{S}{1.40+S}\right)[0.54+0.75(B-0.57)]
$$

\section{Secondary modelling of A}


Figure 2 (up) illustrates the dependence of the maximum relative cell concentration $(A)$ with the glucose concentration $(S)$. It can be observed that the $A$ values increase with the initial sugar concentration of the medium until a stationary value is reached. This behaviour was similar to $\mu_{m}$ and therefore a Monod type equation was used to describe the dependence of $A$ with the sugar concentration (replacing $\mu_{\text {opts }}$ by $A_{o p t s}$ and $K_{S}$ by $K_{S}^{\prime}$ ).

The fit of the experimental data to this equation was satisfactory although the estimation of $K_{S}^{\prime}$ has a considerable error (see statistical parameters in Table 4). This could explain the observed difference between $K_{S}^{\prime}$ and $K_{S}$ (2.52 and $1.40 \mathrm{~g} \mathrm{l}^{-1}$ respectively), although it is also possible that in the media containing small amounts of glucose, the efficiency of glucose consumption for cell conversion decreases. A similar behaviour has been reported by Schepers et al. [40] in $L$. helveticus.

In the batches where the buffering capacity was the controlling factor, the $A$ values ranged from 2.12 to $3.11\left[\log _{10}\left(N / N_{0}\right)_{\max }\right]$, suggesting that the effect of buffering capacity was less significant than that of glucose. This means that even in media where the $p H$ drops fast, the final cell concentration would reach a relatively high level providing that there is sufficient carbon source. Since $A$ continuously increases with increasing buffering capacity, although in a non-linear manner, the value of $A$ corresponding to the highest buffering capacity (1.09 mmoles $\mathrm{HCl} \mathrm{H}^{-1} \mathrm{l}^{-}$ $\left.{ }^{1}\right)$ was considered to be the optimum value $\left(A_{\text {optB }}=3.11\right)$. The relative $A$ values $\left(A / A_{\text {optB }}\right)$ were then plotted (figure 2, down) vs. the buffering capacity $(B)$. The data were also centered on the mean value of the $B$. The following $2^{\text {nd }}$ order polynomial equation was then used to fit the data 


$$
A=3.89\left(\frac{S}{2.52+S}\right)\left[0.95+0.39(B-0.57)-0.64(B-0.57)^{2}\right]
$$

\section{Secondary modelling of $\lambda$}

In order to describe the dependency of the lag time $(\lambda)$ on environmental factors, such as temperature and $p H$, other researchers have modelled $\lambda$ in the same way as the inverse of $\mu_{m}$ $[15,16,38]$, and this strategy was also used in this work. As shown in figure 3, a strong linear correlation existed between $\mu_{m} \lambda$ and $\mu_{m}(\mathrm{r}=0.99, F$-value $=1768.4)$, which could be described by the relationship

$$
\mu_{m} \lambda=\alpha_{3}+\beta_{3} \mu_{m}
$$

The values of the regression parameters are $\alpha_{3}=-0.26 \pm 0.14$ and $\beta_{3}=(4.17 \pm 0.32) \mathrm{h}$. These parameters were obtained from the whole set of batches and are very similar to the ones that would be obtained from the batches with a constant substrate concentration and buffering capacity separately. Equation 9 can then be used to predict the lag phase of L. plantarum by introducing the value of $\mu_{m}$ obtained from equation 7.

\section{Lactic acid production models}

Homofermentative LAB meet their energy requirements for growth and maintenance by producing lactic acid. Maintenance is the energy required for survival or for preservation of cell viability, which is not directly coupled with the synthesis of new cells [45]. The uncoupled lactic

acid production by $L$. plantarum was clearly observed in these batches when lactic acid 
production continued after growth had ceased (data not shown). Based on this, a kinetic representation for lactic acid production could the classical Luedeking-Piret model [46]. This model suggests that the product $(P)$ formation rate depends on the growth rate $(d N / d t)$ and the cell concentration $(N)$. We have expressed the cell concentration in terms of the relative cell population $(X)$

$$
\frac{d P}{d t}=\alpha_{p} \frac{d X}{d t}+\beta_{p} X
$$

Integration of equation 10 between $P_{0} \rightarrow P, 0 \rightarrow X$ and $0 \rightarrow t$ gives

$$
P=P_{0}+\frac{\alpha_{p} A}{1+\exp \left[2+\frac{4 \mu_{m}}{A}(\lambda-t)\right]}+\frac{\beta_{p} A^{2}}{4 \mu_{m}} \cdot \ln \left[\frac{\exp \left(2+\frac{4 \mu_{m} \lambda}{A}\right)+\exp \left(\frac{4 \mu_{m} t}{A}\right)}{1+\exp \left(2+\frac{4 \mu_{m} \lambda}{A}\right)}\right]
$$

In Table 5 the parameters of this equation with their confidence intervals ( $\alpha=0.05$ ), the $F$-value and correlation coefficients are summarized.

\section{Secondary modelling of parameter $\alpha_{p}$}

The values for the growth associated constant $\alpha_{p}$ varies between 0.64 and 0.84 g lactic acid $\left(\log _{10}\right.$ $\left.\left(N / N_{0}\right)\right)^{-1} \mathrm{l}^{-1}$ in the batches where buffering capacity was the controlling factor (Table 5). When $\alpha_{p}$ was plotted against the buffering capacity no clear tendency was observed and the straight line fitting the data was more or less horizontal. For this reason $\alpha_{p}$ was assumed to be constant in our range of buffering capacity. The values of $\alpha_{p}$ in the batches where sugar was the controlling 
factor varied between 0.42 and 0.82 g lactic acid $\left(\log _{10}\left(N / N_{0}\right)\right)^{-1} \mathrm{l}^{-1}$ (Table 5). In this case $\alpha_{p}$ increases with the sugar concentration. Fitting $\alpha_{p} v s$. $S$ data with a $2^{\text {nd }}$ order polynomial equation was not appropriate $(r=0.75)$ but the fit considerably improved by including $3^{\text {rd }}$ or $4^{\text {th }}$ order terms. However, this type of model would be unrealistic and difficult to interpret [47] and for that reason the mean $\alpha_{p}$ value in all batches was used to describe the growth associated lactic acid production $\left(\alpha_{\text {pmean }}=0.71 \pm 0.04\right.$ g lactic acid $\left.\left(\log _{10}\left(N / N_{0}\right)\right)^{-1} \mathrm{l}^{-1}\right)$.

\section{Secondary modelling of parameter $\beta_{p}$}

In the batches where the buffering capacity was the controlling factor, when $\beta_{p}$ was plotted against $B$ not a clear trend was observed and $\beta_{p}$ was considered to be independent of the buffering capacity. The values of $\beta_{p}$ when sugar was the controlling factor ranged from 0 to $0.021 \mathrm{~g}$ lactic acid $\left(\log _{10}\left(N / N_{0}\right)\right)^{-1} \mathrm{l}^{-1} \mathrm{~h}^{-1}$ (Table 5). In one of the batches (when $4 \mathrm{~g} \mathrm{l}^{-1}$ of sugar concentration was used) $\beta_{p}$ was negative and statistically not significant. The significant values of $\beta_{p}$ were then plotted as a function of sugar $(S)$. A lineal equation provide a satisfactory fit of these data $(\mathrm{r}=$ $0.964, F$-value $=114.1$ ) with parametric estimations $\alpha_{4}=0.0007$ (not significant) and $\beta_{4}=$ $0.0011 \pm 0.0003$. The equation that describes $\beta_{p}$ as a function of the sugar concentration will then be

$$
\beta_{p}=0.0011 S
$$

\section{pH model}

Several authors have proposed different approaches to know the dependence between $p H$ and fermentation parameters such as enzyme reaction rates [48], specific growth rates and specific 
activities [49] or by means of re-alkalized fed-batch cultures [50]. In order to model the evolution of $p H$ during fermentation we assumed that the $p H$ drop during growth of L. plantarum was exclusively due to lactic acid production. Thus, with the purpose to establish a relationship between $p H$ and lactic acid production $(P)$ the $p H$ evolution in media with different buffering capacity was studied. In the initial stages of the exponential phase of growth the $p H$ decreased faster in the media with lower buffering capacity, and the final $p H$ value was always lower in media with lower buffering capacity. A mechanistic model [31] was then used assuming that the $p H$ drop with respect to the lactic acid production is directly proportional to the $p H$ minus the final $p H\left(p H_{\min }\right)$

$$
\frac{d p H}{d P}=k\left(p H-p H_{\min }\right)
$$

integration of equation 13 with initial conditions $P_{0}$ and $p H_{0}$ yields

$$
p H=p H_{\min }+\left(p H_{0}-p H_{\min }\right) e^{-k\left(P-P_{0}\right)}
$$

The values of these parameters were estimated by fitting equation 14 to the experimental data for lactic acid and $p H$ (in the batches with different buffering capacities) using the non-linear least squares method. The $p H_{\text {min }}$ values did not show any obvious dependency on the buffering capacity $(B)$, and the mean value $3.21 \pm 0.06$ was used to express the $p H_{\min }$ in all cases. The $k$ values decrease with increasing buffering capacity, which is illustrated in figure 4 . This trend is adequately described by a $2^{\text {nd }}$ order polynomial equation $(r=0.997, F$-value $=865.1)$ and $k$ can be expressed by 


$$
k=5.81-9.95 B+4.53 B^{2}
$$

Finally, a full model of $p H$ can be obtained by introducing equation 14 in equation 11.

$$
p H=p H_{\min }+\left(p H_{0}-p H_{\min }\right) \exp \left\{-k\left[\frac{\alpha_{p} A}{\left.1+\mathrm{e}^{\left[2+\frac{4 \mu_{m}}{A}(\lambda-t)\right.}\right]}+\frac{\beta_{p} A^{2}}{4 \mu_{m}} \cdot \ln \left[\frac{\mathrm{e}^{\left[2+\frac{4 \mu_{m}}{A}(\lambda-t)\right]}+\mathrm{e}^{\left(\frac{4 \mu_{m} t}{A}\right)}}{\left.1+\mathrm{e}^{\left[2+\frac{4 \mu_{m}}{A}(\lambda-t)\right.}\right]}\right]\right)\right\}
$$

\section{Sugar consumption model}

The rate of sugar consumption is mainly a function of three factors: the growth rate, lactic acid production and the rate of substrate uptake for cell maintenance. These three factors can be put together using yields and maintenance coefficients according to the following equation [51]

$$
\frac{d S}{d t}=-\frac{1}{Y_{p / s}} \frac{d P}{d t}-\frac{1}{Y_{x / s}} \frac{d X}{d t}-m_{s} X
$$

Introducing the logistic growth model 3 and the lactic acid production model 11 into equation 17 and integrating, a model describing the change of sugar concentration with time could be obtained. This equation was used to fit the experimental data using the non-linear least squares in order to estimate the parameters $Y_{p / s}, Y_{X / s}$ and $m_{s}$. Though the iterative process converged to a final solution, the parameters obtained were not realistic (and not significant) and depended on the initial values of the estimated parameter. Similar problems in the estimation of yields and maintenance coefficients have been reported before [35,52]. Esener et al. [53] also suggested that 
the estimation of the maintenance coefficients from batch fermentation data has a considerable error.

Based on this it was assumed that the amount of sugar used for cell growth and maintenance was considerably smaller than the one used for lactic acid formation, and could therefore be neglected in the model. Though strictly speaking this is not true, this assumption is often made in lactic acid fermentations and complex bioprocesses [36,45,54]. A new model can then be obtained to describe the consumption of substrate as a function of lactic acid production. Excluding the growth and maintenance terms from equation 17 and integrating with initial conditions $S_{0}$ and $P_{0}$ gives

$$
S_{0}-S=\frac{1}{Y_{p / s}}\left(P-P_{0}\right)
$$

In order to estimate $Y_{p / s}$ (g of lactic acid produced per g of glucose consumed) the glucose and lactic acid concentrations were determined at regular time intervals for a number of batch cultures. The results are shown in Figure 5 and indicate that the glucose uptake and lactic acid formation are linearly correlated $(r=0.99, F$-value $=794.2)$. The estimated $Y_{p / s}$ value was $0.51 \pm 0.02 \mathrm{~g} \mathrm{~g}^{-1}$, which is considerably lower than other reported values for $\mathrm{LAB}$ at optimum conditions with $p H$ control and nutrition rich media [43,45,55]. Our fermentation media contain high amounts of sugars, which mean that the low $Y_{p / s}$ obtained is probably due to the lack of $p H$ control. Low $Y_{p / s}$ values in environments without $\mathrm{pH}$ control have been previously reported [42]. 
Introducing the model for lactic acid production (11) into equation 18 a full model for sugar consumption can be obtained

$$
S=S_{0}-\frac{1}{Y_{p / s}}\left\{\frac{\alpha_{p} A}{\left.1+\mathrm{e}^{\left[2+\frac{4 \mu_{m}}{A}(\lambda-t)\right.}\right]}+\frac{\beta_{p} A^{2}}{4 \mu_{m}} \cdot \ln \left[\frac{\left.\mathrm{e}^{\left[2+\frac{4 \mu_{m}}{A}(\lambda-t)\right]}+\mathrm{e}^{\left(\frac{4 \mu_{m} t}{A}\right)}\right]}{\left.1+\mathrm{e}^{\left[2+\frac{4 \mu_{m}}{A}(\lambda-t)\right.}\right]}\right]\right\}
$$

\section{Simulations of cereal fermentations}

In order to evaluate the ability of the model to describe the biochemical changes taking place during fermentation of L. plantarum, 6 batch cultures in different cereal extracts were monitored. The buffering capacity and the reducing sugar content of the media were initially measured. Values of relative cell population, sugar concentration, lactic acid concentration and $\mathrm{pH}$ were used to calculate the primary and secondary parameters at a given time. The experimental data and the values predicted by the models are depicted in Figure 6. The continuous lines represent the predicted values and the points the experimental results. It is interesting to note that the buffering capacity of a particular cereal medium increases with the percentage of cereal extract, which is probably associated with an increase in its protein and ash content [56].

In wheat media (Figure 6A) both the buffering capacity and the initial sugar content were low ( $S$ $=4.05 \mathrm{~g} \mathrm{l}^{-1}, B=0.23$ mmoles $\mathrm{HCl} \mathrm{pH}^{-1} \mathrm{l}^{-1}$ ), and the predicted cell populations were $15 \%$ lower than the experimental ones at the end of fermentation. This is probably due to variables not taken into account in the models, e.g. specific nutrient requirements for L. plantarum like peptides or aminoacids. The rest of the variables were appropriately described by the models. 
In the medium with 5\% malt (Figure 6B) the initial sugar concentration and buffering capacity were $4.92 \mathrm{~g} \mathrm{l}^{-1}$ and 0.23 mmoles $\mathrm{HCl} \mathrm{pH}^{-1} \mathrm{l}^{-1}$, respectively. In this case all variables are properly modelled with the exception of lactic acid for which the predicted values are underestimated. This could be due to the presence of various fermentable sugars at high levels.

In the fermentations using 30\% barley extract (Figure 6C; $S=5.15 \mathrm{~g} \mathrm{l}^{-1}, B=0.48 \mathrm{mmoles} \mathrm{HCl}$

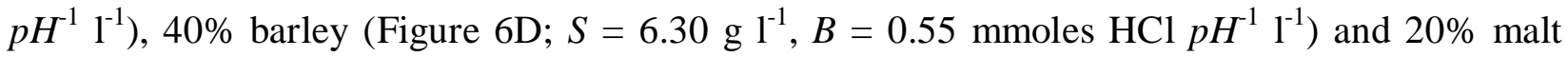
extract (Figure 6E; $S=18.85 \mathrm{~g} \mathrm{l}^{-1}, B=0.56$ mmoles $\mathrm{HCl} p H^{-1} \mathrm{l}^{-1}$ ) the predicted relative cell populations, lactic acid, sugar concentrations and $p H$ are in accordance with the experimental data. The model slightly underestimated the lactic acid production in the $20 \%$ malt medium (Figure 6E).

When citric acid was added (Figure 6F; 30\% barley with $2.2 \mathrm{~g} \mathrm{l}^{-1}$ of citric acid) L. plantarum growth increased as well as the lactic acid production (when compared to Figure 6C, 30\% barley only). This could be attributed to the increased buffering capacity of the medium (0.48 to 0.97 mmoles $\mathrm{HCl} p H^{-1} \mathrm{l}^{-1}$ ), which was also the reason for the higher final $p H$ value (approximately 1 unit higher than in Figure 6C). In this case sugar concentration and $p H$ are well described by the models but relative cell populations and lactic acid are slightly underestimated.

\section{Conclusions}

In this study a model was developed to predict the kinetics of cell growth, lactic acid production, $p H$ drop and sugar consumption in non $p H$-controlled cultures of L. plantarum as a function of the initial sugar concentration and the buffering capacity. The model included four differential 
equations with parameters that were estimated using non-linear regression analysis. Secondary modelling of the derived parameters showed that the maximum specific growth rate $\left(\mu_{m}\right)$ and the relative maximum cell concentration $(A)$ depends on buffering capacity and sugar concentration. The effect of the sugar could be described assuming Monod kinetics, while for the effect of the buffering capacity a linear relationship was used. The lag phase $(\lambda)$ was modelled as the inverse

of the maximum specific growth rate. The growth associated lactic acid production parameter $\alpha_{p}$ was constant, while the non-growth associated production parameter $\beta_{p}$ was a linear function of buffering capacity. Parameter $k$, expressing the constant of lactic acid dissociation to hydrogen ions, depends on the buffering capacity while the minimum $p H$ parameter $\left(p H_{\min }\right)$ was constant. The yield of lactic acid on sugar $\left(Y_{p / s}\right)$ did not depend on sugar or buffering capacity.

The results from the validation studies indicate that the model could adequately describe the biochemical changes during L. plantarum growth in these cereal media with a relatively high buffering capacity, though in some cases the lactic acid and the relative cell populations were slightly underestimated. From an industrial point of view, this study is a first step for the production of new cereal-based functional foods using media with high concentrations of malt, barley and wheat extracts. Our work established a set of equations useful in the optimization of the cultures defined with the purpose of a large-scale production of potentially probiotic beverages. However, more studies are needed in order to determine if the proposed fermentation media exerts some protective effects in the human gut.

\section{References}

[1] J. Nielsen, J. Villadsen, Modelling of microbial kinetics, Chem. Eng. Sci. 47 (1992) 4225- 
4270.

[2] J. Nielsen, K. Nikolajsen, J. Villadsen, Structured modelling of a microbial system: II Experimental verification of a structured lactic acid fermentation model, Biotechnol. Bioeng. 38 (1991) 11-23.

[3] J.F. Van Impe, B.M. Nicolai, M. Schellekens, T. Martens, J.D. Baerdemaeker, Predictive microbiology in a dynamic environment: a system theory approach, Int. J. Food Microb. 25 (1995) 227-249.

[4] J. Baranyi, Stochastic modelling of bacterial lag phase, Int. J. Food Microb. 73 (2002) 203206.

[5] B.Giménez, P. Dalgaard, Modelling and predicting the simultaneous growth of Listeria monocytogenes and spoilage micro-organisms in cold-smoked salmon, J. Appl. Microb. 96 (2004) 96-109.

, J. Baranyi, B. Bjørn Budde, The effect of reuterin on the lag time of single cells of Listeria innocua grown on a solid agar surface at different $\mathrm{pH}$ and $\mathrm{NaCl}$ concentrations, Int. J. Food Microb. 113 (2007) 35-40.

[7] B. Gompertz, On the nature of the function expressive of the law of human mortality, and on a new mode of determining the value of life contingencies, Philos. Trans. R. Soc. London 115 (1825) 513-585.

[8] F.J. Richards, A flexible growth function for empirical use, J. Exp. Bot. 10 (1959) 290-300.

[9] C.J. Stannard, A.P. Williams, P.A. Gibbs, Temperature/growth relationship for phychotrophic food-spoliage bacteria, Food Microb. 2 (1985) 115-122.

[10] J. Schnute, A versatile growth model with statistically stable parameters, Can. J. Fish Aquat. 
Sci. 38 (1981) 1128-1140.

[11] F. Leroy, B. Degeest, L. De Vuyst, A novel area of predictive modelling: describing the functionality of benefical microorganisms in foods, Int. J. Food Microb. 73 (2002) 251-259.

[12] A. Bouguettoucha, B. Balannec, S. Nacef, A. Amrane, A generalised unstructured model for batch cultures of Lactobacillus helveticus, Enzyme Microb. Technol. 41 (2007) 377-382.

[13] A. Bouguettoucha, B. Balannec, A. Amrane, Unstructured generalized models for the analysis of the inhibitory and the nutritional limitation effects on Lactobacillus helveticus growth-Models validation, Biochem. Eng. J. 39 (2008) 566-574.

[14] J.A. Vázquez, M.A. Murado, Unstructured mathematical model for biomass, lactic acid and bacteriocin production by lactic acid bacteria in batch fermentation, J. Chem. Tech. Biotech. 83 (2008) 91-96.

[15] M.H. Zwietering, H.G.A.M. Cuppers, J.C. de Wit, K. van't Riet, Evaluation of data transformations and validation of a model for the effect of temperature on bacterial growth, Appl. Environ. Microb. 60 (1994) 195-203.

[16] T. Wijtzes, J.C. De Wit, J.H.J. Huis in't Veld, K. van't Riet, M.H. Zwietering, Modelling bacterial growth of Lactobacillus curvatus as a function of acidity and temperature, Appl. Environ. Microb. 61 (1995) 2533-2539.

[17] M.G. Gänzle, M. Ehmann, W.P. Hammes, Modelling of growth of Lactobacillus sanfranciscensis and Candida milleri in response to process parameters of sourdough fermentation, Appl. Environ. Microb. 64 (1998) 2616-2623.

, L. Pastoriza, Effects of aeration and $\mathrm{pH}$ gradient on nisin production. A mathematical model, Enzyme Microb. Tech. 29 (2001) 264-273. 
[19] N. Pérez Guerra, L. Pastrana Castro, Enhancement of nisin production by Lactococcus lactis in periodically re-alkalized cultures, Biotech. Appl. Biochem. 38 (2003) 157-167.

, M.A. Murado, Bacteriocin production and $\mathrm{pH}$ gradient: Some mathematical models and their problems, Enzyme Microb. Tech. 37 (2005) 5467.

[21] B. Balannec, A. Bouguettoucha, A. Amrane, Unstructured model for batch cultures without $\mathrm{pH}$ control of Lactobacillus helveticus-Inhibitory effect of the undissociated lactic acid, Biochem. Eng. J. 39 (2008) 566-574.

, L.P. Castro, Dynamic mathematical models to describe the growth and nisin production by Lactococcus lactis subsp. lactis CECT 539 in both batch and re-alkalized fed-batch cultures, J. Food Eng. 82 (2007) 103113.

[23] R. Rozada-Sánchez, A.P. Sattur, K. Thomas, S.S. Pandiella, Evaluation of Bifidobacterium spp. for the production of a potentially probiotic malt-based beverage, Proc. Biochem. 43 (2008) 848-854.

[24] G. Kedia, J.A. Vázquez, S.S. Pandiella, Fermentability of whole oat flour, PeriTec flour and bran by Lactobacillus plantarum, J. Food Eng. 89 (2008) 246-249.

[25] C.C. Chou, J.W. Hou, Growth of bifidobacteria in soymilk and their survival in the fermented soymilk drink during storage, Int. J. Food Microb. 56 (2000) 113-121.

[26] V.S. Jayamanne, M.R. Adams, Survival of probiotic bifidobacteria in buffalo curd and their effect on sensory properties, Int. J. Food Sci. Tech. 39 (2004) 719-725.

[27] D. Charalampopoulos, S.S. Pandiella, C. Webb, Growth studies of potentially probiotic lactic acid bacteria in cereal-based substrates, J. Appl. Microb. 92 (2002) 851-859. 
[28] D. Charalampopoulos, S.S. Pandiella, C. Webb, Evaluation of the effect of malt, wheat and barley extracts on the viability of potentially probiotic lactic acid bacteria under acidic conditions, Int. J. Food Microb. 82 (2003) 133-141.

[29] S.C. Pai, Y.J. Tsa, T.I. Yang, $\mathrm{pH}$ and buffering capacity problems involved in the determination of ammonia in saline water using the indophenol blue spectrophotometric method, Anal. Chim. Acta 434 (2001) 209-216.

[30] G.L. Miller, Use of dinitrosalicylic acid reagent for determination of reducing sugar, Anal. Chem. 31 (1959) 426-428.

[31] N. Draper, H. Smith, Applied regression analysis. John Wiley \& Sons, New York, USA (1998) pp. 369-400 and pp. 257-295.

[32] J.A. Vázquez, M.A. Murado, Mathematical tools for objective comparison of microbial cultures. Application to evaluation of 15 peptones for lactic acid bacteria productions, Biochem. Eng. J. 39 (2008) 276-287.

[33] M.H. Zwietering, I. Jongenburger, F.M. Rombouts, K. Van't Riet, Modeling of the bacterial growth curve, Appl. Environ. Microb. 56 (1990) 1875-1881.

[34] R. Lejeune, R. Callewaert, K. Crabbé, L. De Vuyst, Modelling the growth and bacteriocin production by Lactococcus amylovorus DCE 471 in batch cultivation, J. Appl. Microb. 84 (1998) 159-168.

[35] P. Mercier, L. Yerushalmi, D. Rouleau, D. Dochain, Kinetics of lactic acid fermentation on glucose and corn by Lactobacillus amylophilus, J. Chem. Tech. Biotech. 55 (1992) 111-121.

[36] F. Leroy, L. De Vuyst, A combined model to predict the functionality of the bacteriocinproducing Lactobacillus sakei strain CTC 494, Appl. Environ. Microb. 69 (2003) 1093-1099. 
[37] A. Amrane, Y. Prigent, Analysis of growth and production coupling for batch cultures of Lactobacillus helveticus with the help of an unstructured model, Proc. Biochem. 34 (1999) 1-10.

[38] D.E. Martens, C. Béal, P. Malakar, M.H. Zwietering, K. van't Riet, Modelling the interactions between Lactobacillus curvatus and Enterobacter clocae. I. Individual growth kinetics, Int. J. Food Microb. 51 (1999) 53-65.

[39] W. Messens, P. Neysens, W. Vansieleghem, J. Vanderhoeven, L. De Vuyst, Modeling growth and bacteriocin production by Lactobacillus amylovorus DCE 471 in response to temperature and $\mathrm{pH}$ values used for sourdough fermentations, Appl. Environ. Microb. 68 (2002) 1431-1435.

[40] A.W. Schepers, J. Thibault, C. Lacroix, Lactobacillus helveticus growth and lactic acid production during $\mathrm{pH}$-controlled batch cultures in whey permeate/yeast extract medium. Part I: Multifactor kinetic analysis, Enzyme Microb. Tech. 30 (2002) 176-186.

[41] J. Monod, Recherches sur la croissance de cultures bacteriennes, Herman, Paris (1942).

[42] K.V. Venkatesh, M.R. Okos, P.C. Wankat, Kinetic model of growth and lactic acid production from lactose by Lactobacillus bulgaricus, Proc. Biochem. 28 (1993) 231-241.

[43] C.N. Burgos-Rubio, M. Okos, P. Wankat, Kinetic study of the conversion of different substrates to lacti acid using Lactobacillus, Biotech. Prog. 16 (2000) 305-314.

[44] K. Van’t Riet, J. Tramper, Basic bioreactor design. Marcel Dekker, New York (1991).

[45] F.V. Passos, H.P. Fleming, D.F. Ollis, R.M. Felder, R.F. McFeeters, Kinetics and modelling of lactic acid production by Lactobacillus plantarum, Appl. Environ. Microb. 60 (1994) 26272636. 
[46] R. Luedeking, E.L. Piret, A kinetic study of the lactic acid fermentation batch process at controlled pH, J. Biochem. Technol. Eng. 1 (1959) 393-412.

[47] A.W. Schepers, J. Thibault, C. Lacroix, Lactobacillus helveticus growth and lactic acid production during $\mathrm{pH}$-controlled batch cultures in whey permeate/yeast extract medium. Part II: Kinetic modelling and model validation, Enzyme Microb. Tech. 30 (2002) 187-194.

[48] H. Shimizu, E. Sada, S. Shioya, K.I. Suga, Measurement of enzyme reaction rates using advanced pH control system: Application of repetitive PF system, Biotechnol. Bioeng. 34 (1989) 794-803.

[49] B. Cheirsilp, H. Shimizu, S. Shioya, Modelling and optimization of environmental conditions for kefiran production by Lactobacillus kefiranofaciens, Appl. Microbiol. Biotechnol. 57 (2001) 639-646.

[50] N.P. Guerra, L. Pastrana, Modelling the influence of $\mathrm{pH}$ on the kinetics of both nisin and pediocin production and characterization of their functional properties, Proc. Biochem. 37 (2002) 1005-1015.

[51] P.M. Doran, Homogeneous reactions. In: Bioprocess Engineering Principles. Academic Press, London, UK (1995) pp. 257-295.

[52] A. Holmberg, On the practical identifiability of microbial growth models incorporating Michaelis-Menten type nonlinearities, Mathem. Biosci. 62 (1982) 23-43.

[53] A.A. Esener, J.A. Roels, W.F. Kossen, Theory and application of unstructured growth models. Kinetic and energetic aspects, Biotech. Bioeng. 25 (1983) 2803-2841.

[54] F. Leroy, L. De Vuyst, Growth of the bacteriocin-producing Lactobacillus sakei strain CTC 494 in MRS broth is strongly reduced due to nutrient exhaustion: a nutrient depletion model for the growth of lactic acid bacteria, Appl. Environ. Microb. 67 (2001) 4407-4413. 
[55] L.M.D. Gonçalves, A.M.R.B. Xavier, J.S. Almeida, M.J.T. Carrondo, Concomitant substrate and product inhibition kinetics in lactic acid production, Enzyme Microb. Tech. 13 (1991) 314319.

[56] I. Marklinder, L. Johansson, Sour dough fermentation of barley flours with varied content of mixed-linked (1 $\rightarrow 3$ ), (1 $\rightarrow 4) \beta$-D-glucans, Food Microb. 12 (1995) 363-371. 


\section{FIGURE CAPTIONS}

Figure 1: Maximum specific growth rate $\left(\mu_{m}\right)$ as a function of the initial glucose concentration of the medium (up) and as a function of the buffering capacity (down). The data points for $\mu_{m}$ are obtained from Table 3.

Figure 2: Maximum relative cell concentration $(A)$ as a function of the initial glucose concentration of the medium (up) and as a function of the buffering capacity (down). The data points for $\mu_{m}$ are obtained from Table 3 .

Figure 3: $\mu_{m} \lambda$ as a function of $\mu_{m}$. The data points are obtained from Table 3 .

Figure 4: Parameter $k$ as a function of buffering capacity.

Figure 5: $S_{0}-S$ as a function of $P-P_{0}$. The data points are obtained from 5 batch cultures.

Figure 6: Experimental data (symbols) and model predictions (lines) for L. plantarum in: (A) 20\% wheat extract; (B) 5\% malt extract; (C) 30\% barley extract; (D) 40\% barley extract; (E) 20\% malt extract; and (F) 30\% barley extract with $2.2 \mathrm{~g} \mathrm{l}^{-1}$ citric acid. $X$ ( ), relative cell concentration; $L(\bigcirc)$, lactic acid concentration; $p H(\square)$ and $S(\diamond)$, sugar concentration. 


\section{TABLE CAPTIONS}

Table 1: Composition of the synthetic media used for the development of the model.

Table 2: Notation used with units.

Table 3: Optimum parameter values for the logistic model 3 describing L. plantarum growth in synthetic media of different buffering capacity and glucose concentration. The values are the means with the corresponding confidence intervals $(\alpha=0.05) . F$-values are the results of the $F$ Fisher test $(\alpha=0.05)$ for 3 model degrees freedom and 21-30 error degrees freedom. $\mathrm{r}=$ correlation coefficient between observed and predicted data.

Table 4: Parameters for the secondary models expressing $\mu_{m}$ and $A$ as a function of sugar concentration and buffering capacity. $\mathrm{CI}=$ confidence intervals $(\alpha=0.05)$. F-values are the results of the F-Fisher test $(\alpha=0.05)$ for 2 model degrees freedom and 6-8 error degrees freedom. $\mathrm{r}=$ correlation coefficient between observed and predicted data.

Table 5: Optimum parameters for equation 14 describing lactic acid production during $L$. plantarum growth in synthetic media of different buffering capacity and sugar concentration. The values are the means with the corresponding confidence intervals $(\alpha=0.05)$. F-values are the results of the $F$-Fisher test $(\alpha=0.05)$ for 2 model degrees freedom and 6-12 error degrees freedom. $\mathrm{r}=$ correlation coefficient between observed and predicted data. $\mathrm{NS}=$ not significant. 


\section{FIGURES}

Figure 1
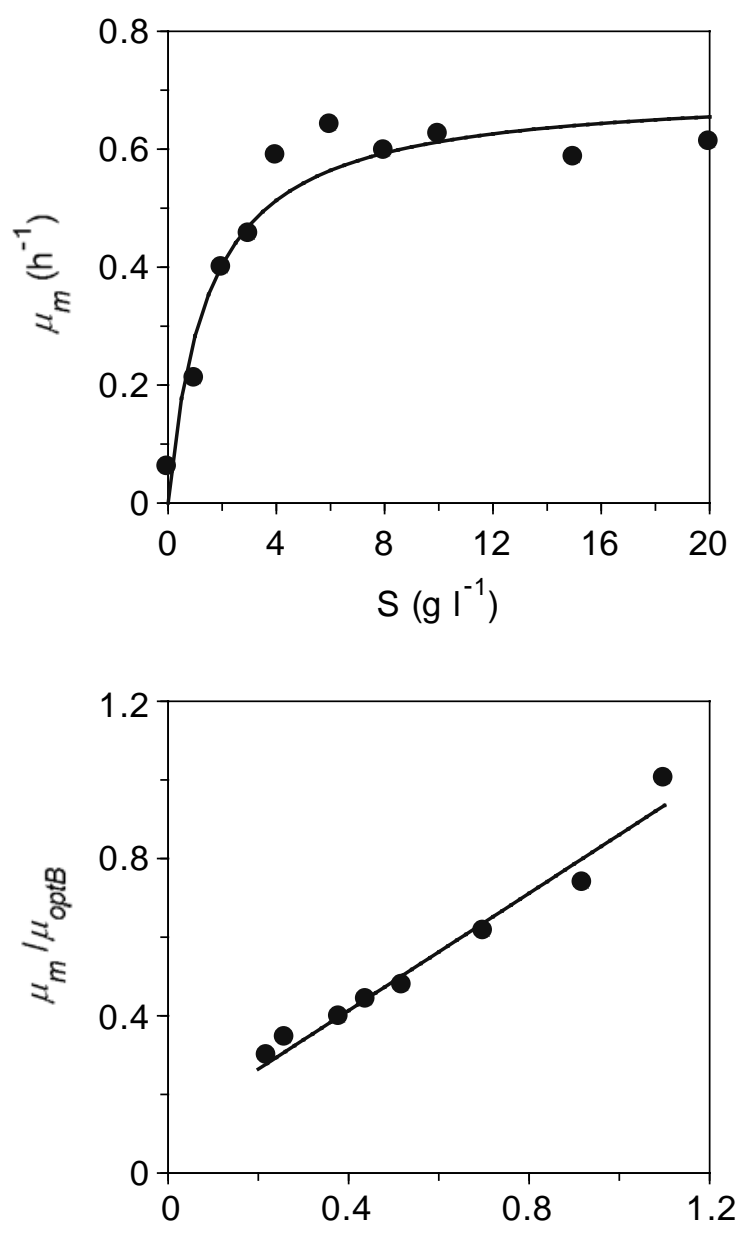

Buffering capacity (mmoles $\mathrm{HCl} \mathrm{pH}^{-1} \mathrm{I}^{-1}$ ) 
Figure 2
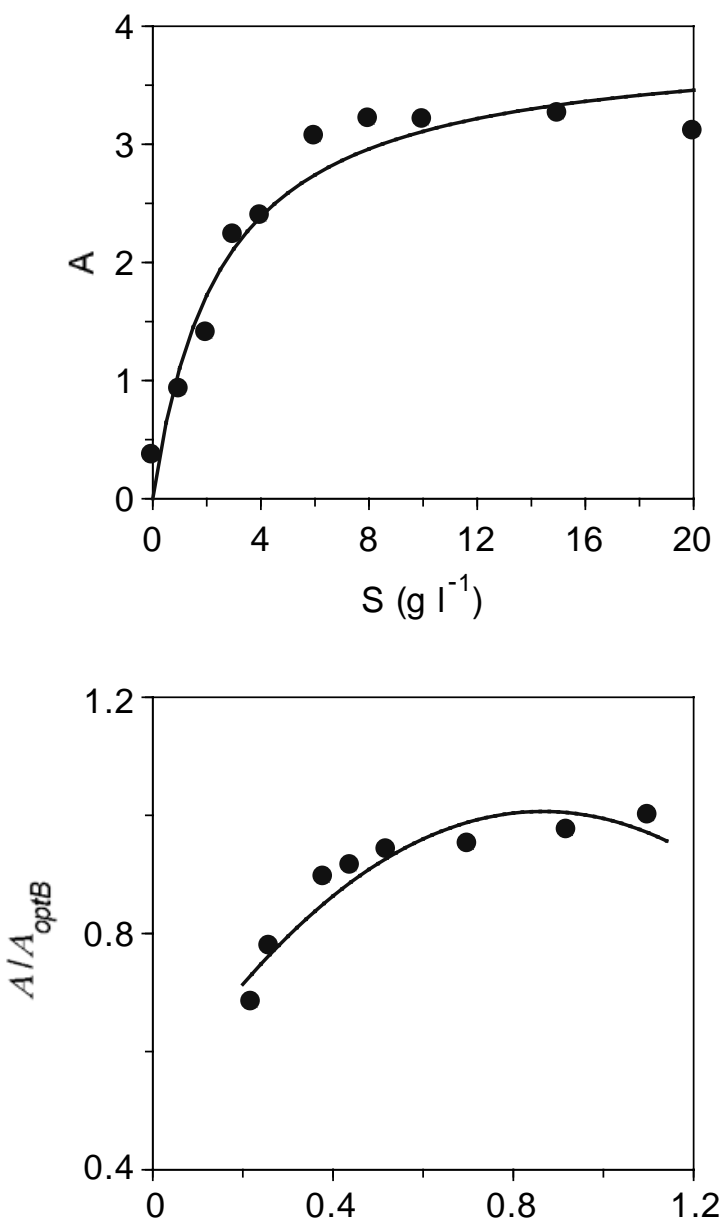

Buffering capacity (mmoles $\mathrm{HCl} \mathrm{pH}^{-1} \mathrm{I}^{-1}$ ) 
Figure 3

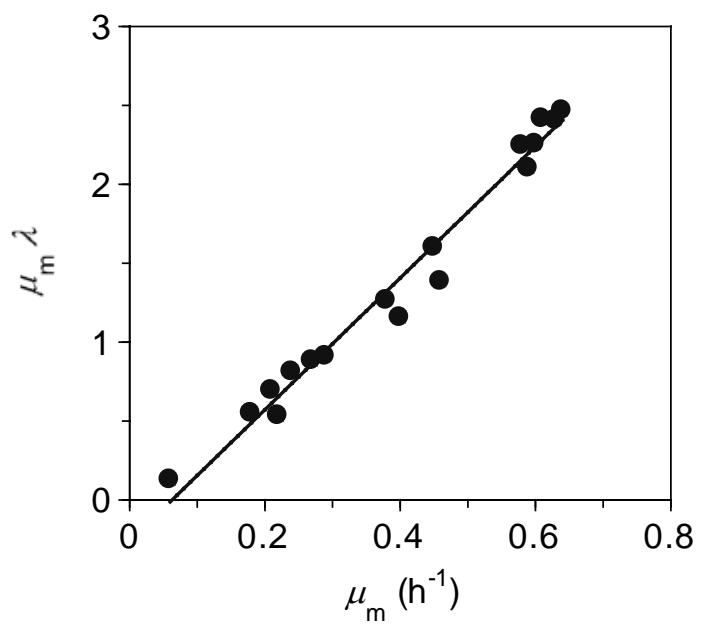




\section{Figure 4}

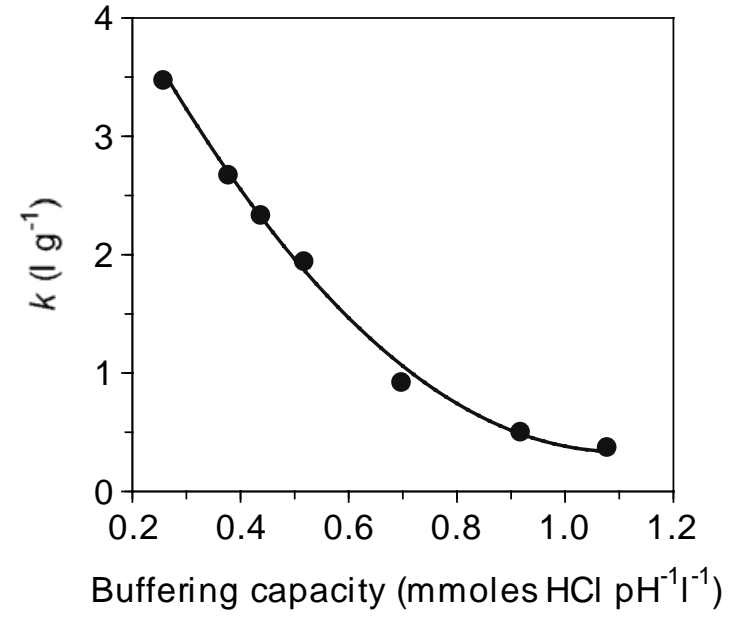


Figure 5

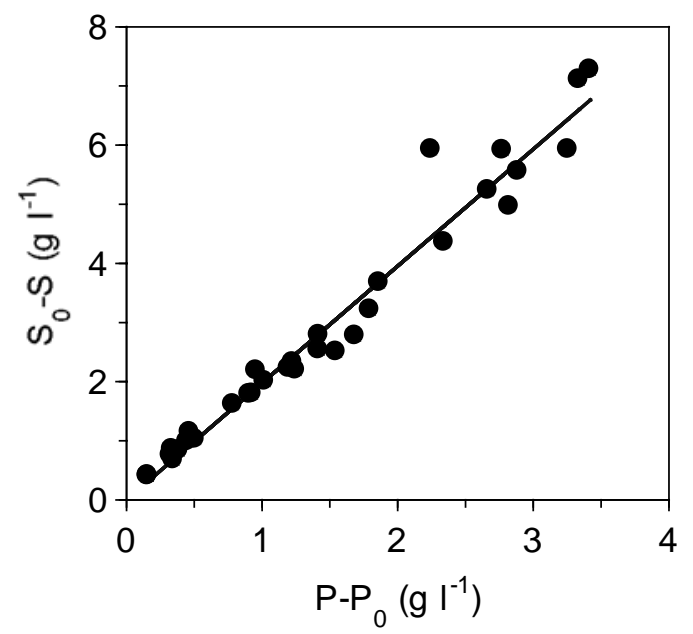




\section{Figure 6}
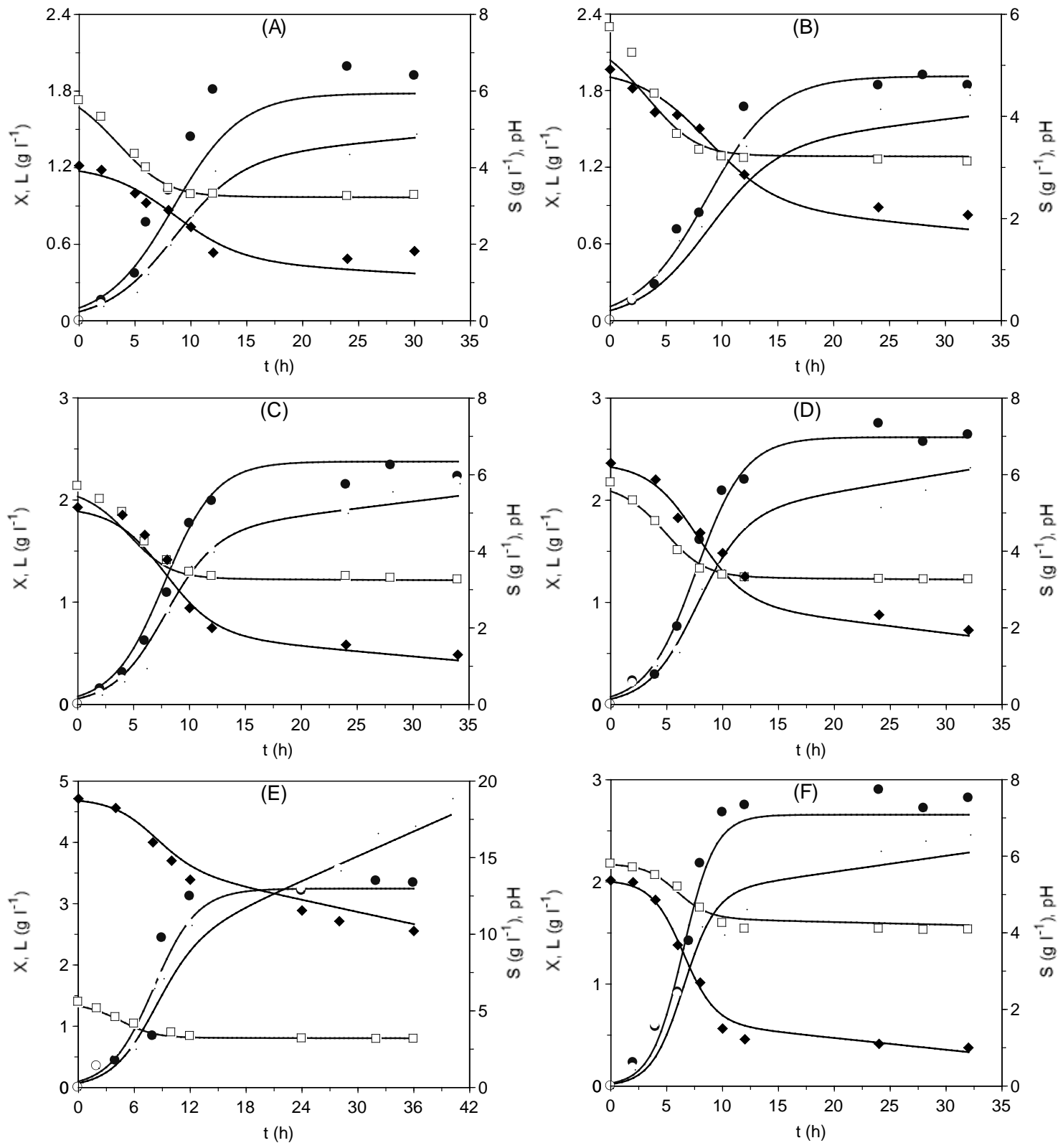


\section{TABLES}

\section{Table 1}

\begin{tabular}{|c|c|}
\hline Controlling factor & Nutrients concentrations a \\
\hline Buffering capacity (mmoles $\left.\left.\mathrm{HCl} \mathrm{pH}^{-1}\right|^{-1}\right)$ : 0.22, 0.26, 0.39, 0.44, & FAN: $150 \mathrm{mg} \mathrm{l-1}$ \\
\hline $0.53,0.70,0.92,1.09$ & Glucose: $20 \mathrm{~g} \mathrm{l-1}$ \\
\hline \multirow[t]{2}{*}{ Glucose concentrations $\left(\mathrm{g} \mathrm{l}^{-1}\right): 0,1.2,3,4,6,8,10,15,20$} & FAN: $150 \mathrm{mg} \mathrm{l-1}$ \\
\hline & Buffering capacity: 1.09 mmoles $\left.\mathrm{HCl} \mathrm{pH}^{-1}\right|^{-1}$ \\
\hline
\end{tabular}




\section{Table 2}

$X: \quad$ Biomass as relative cell population, dimensionless $\left(\log _{10}\left(N / N_{0}\right)\right)$

$t: \quad$ Time, $\mathrm{h}$

N: $\quad$ Cell concentration, cfu $\mathrm{ml}^{-1}$

No: $\quad$ Initial cell concentration, cfu $\mathrm{ml}^{-1}$

$\mu_{m}: \quad$ Maximum specific growth rate, $\mathrm{h}^{-1}$

$\lambda$ : $\quad$ Growth lag phase, $\mathrm{h}$

A : $\quad$ Maximum relative cell population, $\log _{10}\left(N / N_{0}\right)_{\max }$

$\mu_{\text {opts }}$ : Maximum specific growth rate at the optimum sugar concentration, $\mathrm{h}^{-1}$

$K_{s}$ : $\quad$ Half-saturation constant, $\mathrm{g}^{-1}$

S: $\quad$ Sugar concentration, $\mathrm{g} \mathrm{H}^{-1}$

So: Initial sugar concentration, $\mathrm{g}^{-1}$

$B$ : $\quad$ Buffer capacity, mmoles $\left.\mathrm{HCl} \mathrm{pH}^{-1}\right|^{-1}$

$\alpha_{1}$ : $\quad$ Regresion parameter, dimensionless

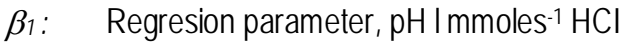

$\mu_{\text {opt }}$ : Maximum specific growth rate at the conditions where $S$ and $B$ are at their optimum, $h^{-1}$

Aopts: Maximum $A$ value at the optimal glucose concentration, dimensionless

$K^{\prime} s$ : Half-saturation constant, $g^{-1}$

AoptB: Maximum $A$ value at the optimal buffer capacity, dimensionless

$\alpha_{2}: \quad$ Regresion parameter, dimensionless

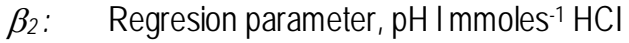

$\mathrm{C}_{2}$ : $\quad$ Regresion parameter, $\mathrm{pH}^{2} \mathrm{R}^{2}$ mmoles $^{-2} \mathrm{HCl}$

$A_{\text {opt }}$ : Maximum $A$ value at the conditions where $S$ and $B$ are at their optimum, dimensionless

$\alpha_{3}: \quad$ Regresion parameter, dimensionless

$\beta_{3}$ : $\quad$ Regresion parameter, $\mathrm{h}$

$P$ : $\quad$ Lactic acid concentration, $g^{-1}$

$P_{0}$ : Initial lactic acid concentration, $\mathrm{g}^{-1}$

$\alpha_{p}$ : $\quad$ Growth associated constant, g lactic acid $\left.\left(\log _{10}\left(N / N_{0}\right)\right)^{-1}\right|^{-1}$

$\beta_{3}$ : $\quad$ Non-growth associated constant, g lactic acid $\left.\left(\log _{10}\left(N / N_{0}\right)\right)^{-1}\right|^{-1} h^{-1}$

$k$ : $\quad$ Constant, $\mathrm{g} \mathrm{t}^{-1}$

$Y_{p / s}$ : Yield of lactic acid production on substrate, $g$ (lactic acid) $g^{-1}$ (sugar)

$Y_{x / s}$ : $\quad$ Relative cell population yield on substrate, $\log _{10}\left(N / N_{0}\right) g^{-1}$ (sugar) I

$m_{s}: \quad$ Relative cell maintenance coefficient, $g$ (sugar) $\left.\right|^{-1}\left[\log _{10}\left(N / N_{0}\right)\right]^{-1} h^{-1}$ 


\section{Table 3}

\begin{tabular}{|c|c|c|c|c|c|c|}
\hline Buffering capacity & $\mu_{m}$ & $A$ & $\lambda$ & Data points & $F$-value & $r$ \\
\hline 0.22 & $0.182 \pm 0.026$ & $2.125 \pm 0.102$ & $3.008 \pm 0.840$ & 33 & 1101.2 & 0.988 \\
\hline 0.26 & $0.210 \pm 0.035$ & $2.420 \pm 0.122$ & $3.293 \pm 0.955$ & 24 & 955.4 & 0.991 \\
\hline 0.39 & $0.242 \pm 0.052$ & $2.784 \pm 0.181$ & $3.346 \pm 1.231$ & 24 & 570.3 & 0.984 \\
\hline 0.44 & $0.269 \pm 0.038$ & $2.845 \pm 0.129$ & $3.274 \pm 0.805$ & 33 & 1155.6 & 0.989 \\
\hline 0.53 & $0.291 \pm 0.044$ & $2.928 \pm 0.144$ & $3.121 \pm 0.837$ & 33 & 1025.1 & 0.987 \\
\hline 0.70 & $0.375 \pm 0.067$ & $2.958 \pm 0.164$ & $3.367 \pm 0.830$ & 33 & 829.2 & 0.983 \\
\hline 0.92 & $0.450 \pm 0.044$ & $3.031 \pm 0.083$ & $3.550 \pm 0.382$ & 33 & 3664.9 & 0.996 \\
\hline 1.09 & $0.612 \pm 0.087$ & $3.109 \pm 0.084$ & $3.943 \pm 0.418$ & 33 & 2921.0 & 0.995 \\
\hline Sugar & $\mu m$ & $A$ & $\lambda$ & Data points & $F$-value & $r$ \\
\hline 0 & $0.061 \pm 0.023$ & $0.367 \pm 0.031$ & $2.063 \pm 1.258$ & 10 & 392.6 & 0.991 \\
\hline 1 & $0.211 \pm 0.077$ & $0.925 \pm 0.051$ & $2.520 \pm 0.895$ & 30 & 615.2 & 0.970 \\
\hline 2 & $0.399 \pm 0.088$ & $1.403 \pm 0.045$ & $2.891 \pm 0.394$ & 25 & 1766.9 & 0.992 \\
\hline 3 & $0.456 \pm 0.062$ & $2.232 \pm 0.049$ & $3.033 \pm 0.363$ & 33 & 3915.9 & 0.995 \\
\hline 4 & $0.589 \pm 0.141$ & $2.394 \pm 0.088$ & $3.564 \pm 0.504$ & 29 & 1395.2 & 0.990 \\
\hline 6 & $0.641 \pm 0.047$ & $3.067 \pm 0.044$ & $3.845 \pm 0.193$ & 29 & 10040.5 & 0.999 \\
\hline 8 & $0.597 \pm 0.063$ & $3.214 \pm 0.074$ & $3.772 \pm 0.331$ & 29 & 3995.3 & 0.997 \\
\hline 10 & $0.625 \pm 0.043$ & $3.208 \pm 0.046$ & $3.845 \pm 0.203$ & 27 & 9785.6 & 0.999 \\
\hline 15 & $0.586 \pm 0.054$ & $3.259 \pm 0.067$ & $3.829 \pm 0.309$ & 42 & 4908.3 & 0.996 \\
\hline 20 & $0.612 \pm 0.087$ & $3.109 \pm 0.084$ & $3.943 \pm 0.418$ & 33 & 2921.0 & 0.995 \\
\hline
\end{tabular}




\section{Table 4}

\begin{tabular}{|c|c|c|c|c|c|}
\hline Controlling factor & Equation & Parameter & Value $\pm \mathrm{Cl}$ & $F$-value & $r$ \\
\hline \multirow[t]{2}{*}{ Glucose } & 4 & $\mu$ opts $\left(\mathrm{h}^{-1}\right)$ & $0.703 \pm 0.099$ & 405.0 & 0.965 \\
\hline & & $K_{s}\left(\mathrm{~g} \mathrm{l}^{-1}\right)$ & $1.482 \pm 0.963$ & & \\
\hline \multirow[t]{3}{*}{ Buffering capacity } & 5 & $\mu_{\text {opts }}\left(\mathrm{h}^{-1}\right)$, from table 2 & $0.612 \pm 0.087$ & 623.04 & 0.983 \\
\hline & & $\alpha_{1}$ & $0.540 \pm 0.041$ & & \\
\hline & & $\beta_{1}\left(\mathrm{pH}\right.$ I mmoles $\left.{ }^{-1} \mathrm{HCl}\right)$ & $0.745 \pm 0.138$ & & \\
\hline \multirow[t]{2}{*}{ Glucose } & Similar to 4 & Aopts & $3.893 \pm 0.632$ & 429.9 & 0.973 \\
\hline & & $K_{s}^{\prime}\left(\mathrm{g}^{-1}\right)$ & $2.519 \pm 1.420$ & & \\
\hline \multirow[t]{5}{*}{ Buffering capacity } & 8 & Aopts, from table 2 & $3.109 \pm 0.084$ & 1378.2 & 0.951 \\
\hline & & $\alpha_{2}$ & $0.949 \pm 0.056$ & & \\
\hline & & $\beta_{2}\left(\mathrm{pH}\right.$ I mmoles $\left.{ }^{-1} \mathrm{HCl}\right)$ & $0.391 \pm 0.147$ & & \\
\hline & & $\mathrm{C}_{2} \quad\left(\mathrm{pH}^{2} \quad \mathrm{I}^{2}\right.$ mmoles $^{-2}$ & $-0.661 \pm 0.508$ & & \\
\hline & & $\mathrm{HCl})$ & & & \\
\hline
\end{tabular}




\section{Table 5}

\begin{tabular}{|c|c|c|c|c|c|}
\hline Buffering capacity & $\alpha_{p}$ & $\beta_{p}$ & Data points & $F$-value & $r$ \\
\hline 0.22 & $0.781 \pm 0.081$ & $0.022 \pm 0.005$ & 14 & 1623.7 & 0.994 \\
\hline 0.26 & $0.691 \pm 0.062$ & $0.021 \pm 0.004$ & 14 & 2757.3 & 0.997 \\
\hline 0.39 & $0.747 \pm 0.086$ & $0.014 \pm 0.005$ & 12 & 1257.0 & 0.996 \\
\hline 0.44 & $0.643 \pm 0.074$ & $0.023 \pm 0.005$ & 14 & 2220.4 & 0.997 \\
\hline 0.53 & $0.841 \pm 0.078$ & $0.006 \pm 0.005$ & 13 & 1340.6 & 0.994 \\
\hline 0.70 & $0.722 \pm 0.075$ & $0.016 \pm 0.005$ & 13 & 1638.0 & 0.997 \\
\hline 0.92 & $0.713 \pm 0.074$ & $0.023 \pm 0.005$ & 13 & 1736.4 & 0.996 \\
\hline 1.09 & $0.752 \pm 0.032$ & $0.021 \pm 0.002$ & 13 & 8316.2 & 0.999 \\
\hline Sugar & $\alpha_{p}$ & $\beta_{p}$ & Data points & F-value & $r$ \\
\hline 1 & $0.420 \pm 0.092$ & 0.000 (NS) & 8 & 119.6 & 0.963 \\
\hline 2 & $0.702 \pm 0.060$ & 0.000 (NS) & 10 & 1049.4 & 0.991 \\
\hline 3 & $0.707 \pm 0.019$ & $0.003 \pm 0.001$ & 10 & 9817.6 & 0.999 \\
\hline 4 & $0.667 \pm 0.170$ & -0.001 (NS) & 10 & 114.0 & 0.981 \\
\hline 6 & $0.720 \pm 0.049$ & $0.007 \pm 0.003$ & 11 & 2236.2 & 0.997 \\
\hline 8 & $0.745 \pm 0.145$ & $0.013 \pm 0.008$ & 11 & 341.5 & 0.985 \\
\hline 10 & $0.822 \pm 0.103$ & $0.012 \pm 0.006$ & 11 & 705.1 & 0.993 \\
\hline 15 & $0.715 \pm 0.123$ & $0.015 \pm 0.007$ & 10 & 489.7 & 0.990 \\
\hline 20 & $0.752 \pm 0.032$ & $0.021 \pm 0.002$ & 13 & 8316.2 & 0.999 \\
\hline
\end{tabular}

